\title{
Struktur dan Vibrasi Carbamida: Eksperimen dan Kajian Teoritik Density functional theory (DFT)
}

\author{
Laode A. Kadir*1, Dian Permana ${ }^{2}$, loan Ramadhan ${ }^{3}$ \\ ${ }^{1,3}$ Universitas Halu Oleo; \\ ${ }^{2}$ Universitas Sembilanbelas November Kolaka \\ e-mail: *11 laode.kadir90@uho.ac.id, ${ }^{2}$ asopermana@gmail.com, 3 ramadhan305@gmail.com
}

\begin{abstract}
Abstrak
Pada penelitian analisis spektrum vibrasi dilakukan menggunakan spektroskopi infra merah pada rentang 500-4000 $\mathrm{cm}^{-1}$ untuk molekul karbamida. Struktur molekul, frekuensi vibrasi dasar dan intensitas pita vibrasi diinterpretasikan dengan bantuan optimasi struktur dan perhitungan medan gaya koordinat normal berdasarkan metode density functional theory (DFT). Penugasan getaran yang lengkap dari bilangan gelombang dibuat pada dasar distribusi energi potensial. Hasil B3LYP/6-31G skala memperlihatkan kesesuaian dengan nilai ekperimen.
\end{abstract}

Kata kunci : Carbamida, DFT, Eksperimen, Vibrasi

\section{PENDAHULUAN}

Karbamida memiliki nama lain yang juga sering dipakai yaitu karbamida resin, isourea, karbonil diamida dan karbonildiamina. Tetapi molekul ini lebih banyak dikenal dengan nama urea. Molekul ini merupakan molekul organik pertama yang berhasil disintesis dari senyawa anorganik dengan ciri fisik berbentuk padat putih (Morrison \& Siddick 2003).

Beberapa studi ekperimen mengenai karbamida sudah dilaporkan, seperti yang sudah dilakukan (Manivannan dkk. 2011), dan juga seperti yang sudah dilaporkan oleh (Grdadolnik \& Maréchal 2002). Mereka telah banyak mengkaji aspek fisik dan kimia dari karbamida secara eksperimen. Sepanjang pengetahuan penulis perbandingan kajian teoritik dan hasil eksperimen karbamida, khususnya analisis vibrasi (spektroskopi Infra Merah) belum dilaporkan sebelumnya, sehingga penulis tertarik untuk mengkaji aspek ini.

Salah satu metode yang digunakan untuk perhitungan secara komputasi adalah Density Functional Theory (DFT). Metode ini memiliki keuntungan dibanding metode sebelumnya seperti ab initio dan semi empiris karena bisa menghitung suatu senyawa kompleks sekalipun dengan lebih sederhana dan cepat dengan hasil yang tidak jauh berbeda dari data eksperimen (Hastiawan 2013). Metode DFT mengandalkan densitas elektron sebagai besaran dasarnya sehingga persamaan Scrodinger dapat diselesaikan dengan lebih sederhana (Kusuma \& Windarti 2013). Untuk sistem logam transisi, umumnya metode DFT mengarah pada struktur dan vibrasi energi yang lebih akurat dibandingkan dengan metode HF (Govindarajan, dkk. 2010).

Beberapa hasil penelitian sebelumnya menunjukkan hasil yang baik dalam penggunaan metode DFT antara lain: meramalkan struktur elektronik dan sifat transisi spin kompleks (Sundaraganesan, dkk 2012), memprediksi energi dan geometri molekul (Pongajow \& Hastiawan, 2017), serta mempelajari termokimia reaksi dan vibrasi (Premkumar, dkk. 2014).

Penggunaan metode DFT dengan hasil yang baik dalam berbagai penelitian, memberikan harapan yang besar bagi peneliti untuk melakukan kajian tentang analisis vibrasi molekul Karbamida, mengingat bahwa sampai saat ini molekul ini masih kurang dipelajari dan informasi yang mencakup data teoritis dari molekul ini masih sedikit.

\section{METODE PENELITIAN}

Sampel karbamida diperoleh dari Sigma Aldrich Chemical Company dengan kemurnian lebih dari 98\%. Sampel ini berbentuk padat putih. Spektra FTIR di ukur dengan menggunakan Spektrometer Alpha Bruker 
66v/S pada rentang 500-4000 $\mathrm{cm}^{-1}$. Spektrum FTIR secara teoritik diprediksi menggunakan metode DFT, fungsi B3LYP, basis set 6-31G(d) pada perangkat lunak Gaussian 03W (Frisch dkk., 2003).

\section{HASIL DAN PEMBAHASAN}

\subsection{Geometri Molekul}

Untuk mendapatkan keakuratan hasil perhitungan dan validasi metode yang digunakan maka dibuat pemodelan untuk molekul karbamida guna dibandingkan antara data sebelum optimasi dan setelah optimasi geometri. Gambar 1 berikut ini adalah hasil sebelum dan setelah optimasi geometri yang diperoleh dengan metode komputasi.

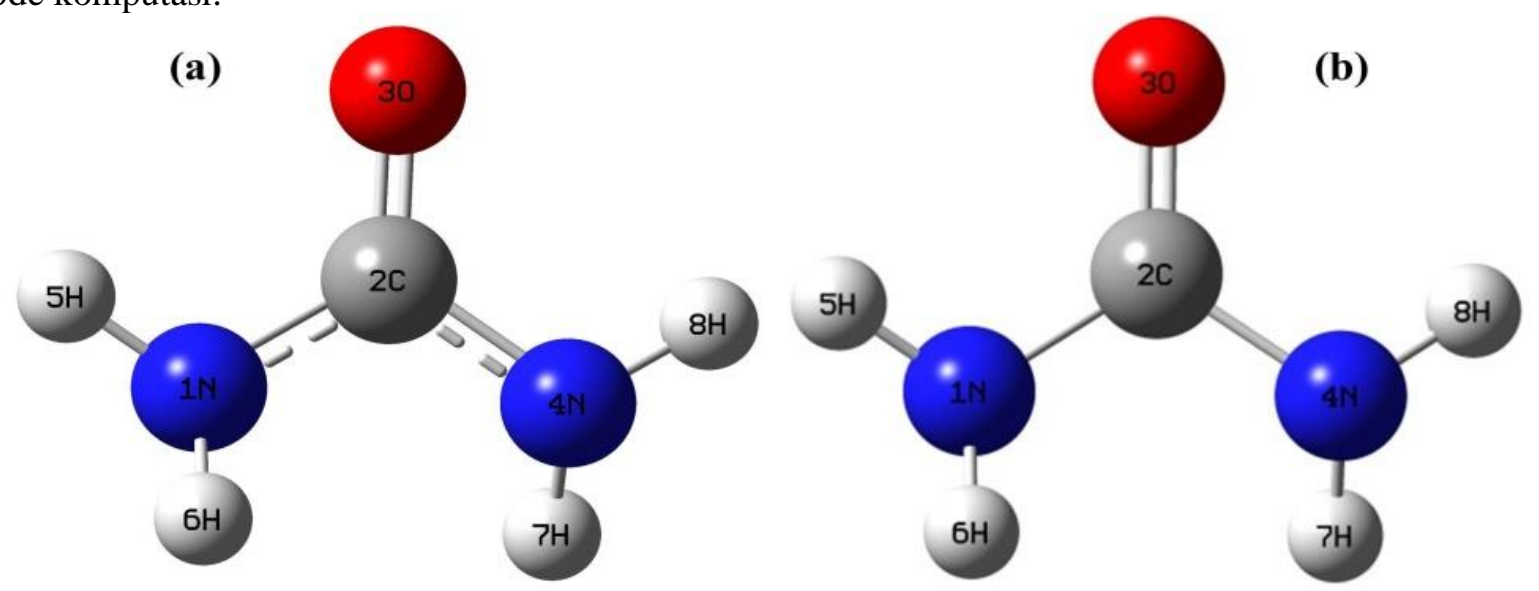

Gambar 1. Geometri karbamida (a) struktur sebelum optimasi (b) struktur setelah optimasi

Perbandingan panjang ikatan karbamida sebelum dan sesudah optimasi menunjukkan hasil yang berbeda seperti ditampilkan pada Tabel 1 . Rata-rata selisih panjang ikatan $\sim 0,01 \AA$ dan sudut ikatan sekitar $\sim 0,2^{\circ}$. Misalnya panjang ikatan $2 \mathrm{C}-1 \mathrm{~N}$, hasil analisis panjang ikatan sebelum optimasi adalah $1.34967 \AA$ (B3LYP), sedangkan panjang ikatan setelah optimasi geometri adalah $1.3914666 \AA$. Sudut ikatan 3O-2C-1N dari data sebelum optimasi adalah $123,514^{\circ}$ sedangkan data optimasi geometri adalah $123.204^{\circ}$ (B3LYP). Adanya selisih panjang dan sudut ikatan ini menjadi indikasi bahwa struktur yang karbamida yang dibangun telah optimal sehingga struktur ini bias digunakan selanjutnya untuk analisis vibrasi (Kusuma \& Windarti 2013)

Tabel 1. Panjang ikatan dan sudut ikatan hasil optimasi geometri

\begin{tabular}{|l|c|c|c|c|}
\hline \multirow{2}{*}{ Jenis Ikatan } & \multicolumn{2}{|c|}{ Sebelum Optimasi Geometri } & \multicolumn{2}{c|}{ Setelah Optimasi Geometri } \\
\cline { 2 - 5 } & $\begin{array}{c}\text { Panjang Ikatan } \\
(\AA)\end{array}$ & $\begin{array}{c}\text { Sudut Ikatan } \\
\left({ }^{\circ}\right)\end{array}$ & $\begin{array}{c}\text { Panjang Ikatan } \\
(\AA)\end{array}$ & $\begin{array}{c}\text { Sudut Ikatan } \\
\left({ }^{\circ}\right)\end{array}$ \\
\hline $2 \mathrm{C}-1 \mathrm{~N}$ & 1.34967 & & 1.3914666 & \\
\hline $3 \mathrm{O}-2 \mathrm{C}$ & 1.21875 & 123.51404 & 1.220047 & 123.2041071 \\
\hline $4 \mathrm{~N}-2 \mathrm{C}$ & 1.34967 & 112.97635 & 1.3914818 & 113.5919888 \\
\hline $5 \mathrm{H}-1 \mathrm{~N}$ & 1.01257 & 113.10448 & 1.0118957 & 112.3031857 \\
\hline $6 \mathrm{H}-1 \mathrm{~N}$ & 1.00984 & 115.78031 & 1.0128336 & 117.0566342 \\
\hline $7 \mathrm{H}-4 \mathrm{~N}$ & 1.00986 & 115.77167 & 1.0128366 & 117.0543194 \\
\hline 8H-4N & 1.01257 & 113.09736 & 1.0118978 & 112.3008332 \\
\hline
\end{tabular}

\subsection{Muatan Parsial Atom}


Aplikasi perhitungan mekanika kuantum kedalam system molekul, penentuan muatan atom memiliki peranan yang cukup penting. Muatan atom Mulliken ditentukan berdasarkan kerapatan populasi elektron pada tiap atom yang didefinisikan sebagai basis fungsi (Sundaraganesan, dkk. 2012).

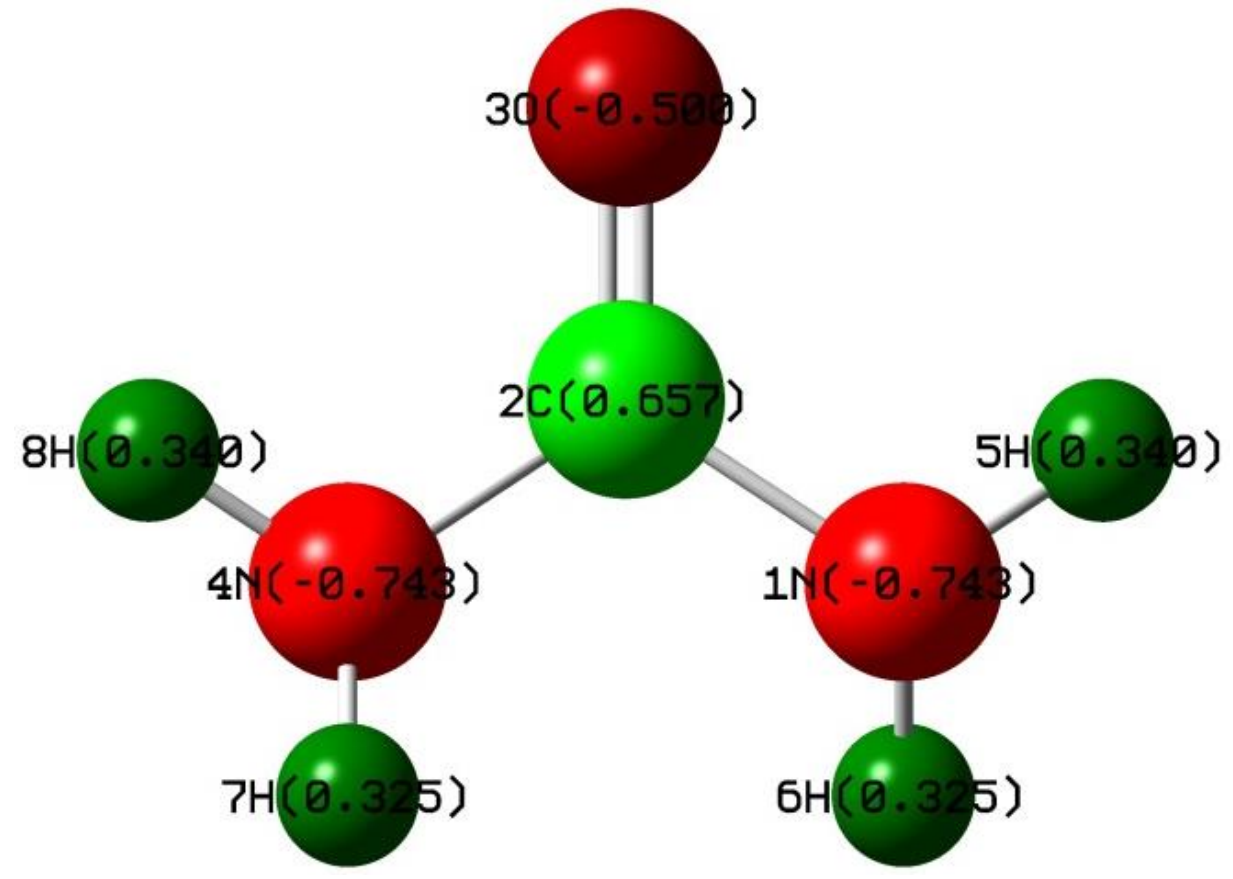

Gambar 2. Distribusi muatan Mulliken molekul karbamida

Atom karbon (2C) memiliki muatan positif tertinggi dibandingkan dengan atom positif lain sebesar 0,657. Dalam struktur karbamida semua atom hidrogen bermuatan positif sebesar 0,340 hal ini memungkinkan atom hidrogen berinteraksi dengan atom yang elektronegatif seperti atom hidrogen. Adanya atom oksigen dan atom nitrogen yang bermuatan negatif cukup besar yaitu $-0,500$ dan $-0,743$ yang mampu berperan sebagai atom donor, disisi lain atom hidrogen bermuatan positif sehingga hal ini memungkinkan terjadinya ikatan hidrogen intramolekuler dalam fasa kristalin.

\subsection{Analisis Vibrasi}

Penentuan secara detail mode vibrasi molekul karbamida, dilakukan secara eksperimen dan perhitungan secara komputasi menggunakan tingkat teori DFT/B3LYP dengan basis set 6-31G(d) untuk semua atom. Gambar 3 secara visual merupakan perbandingan spektrum FTIR hasil eksperimen dengan hasil perhitungan. Pola spektrum FTIR hasil eksperimen (Gambar 4a) dengan hasil perhitungan (Gambar 4b) memiliki kemiripan. Modus vibrasi ikatan molekul karbamida secara karakteristik terlihat di daerah bilangan gelombang $1654 \mathrm{~cm}^{-1}$ untuk regangan $\mathrm{C}=\mathrm{O}$ karbonil dan $1397 \mathrm{~cm}^{-1}$ untuk regangan $\mathrm{C}-\mathrm{N}$, sedangkan dari hasil observasi komputasi vibrasi regangan $\mathrm{C}=\mathrm{O}$ karbonil dan regangan $\mathrm{C}-\mathrm{N}$ berada pada bilangan gelombang 1840 $\mathrm{cm}^{-1}$, dan $1426 \mathrm{~cm}^{-1}$. Selanjutnya, modus vibrasi regangan ikatan $\mathrm{N}-\mathrm{H}$ berada di daerah bilangan gelombang $3387 \mathrm{~cm}^{-1}$ sedangkan hasil perhitungan diperoleh pada bilangan gelombang $3556 \mathrm{~cm}^{-1}$.

Vibrasi karbonil amida menunjukkan vibrasi dengan intensitas yang kuat baik secara eksperimen maupun secara komputasi. Rentang vibrasi $\mathrm{C}=\mathrm{O}$ amida ini dipengaruhi oleh beberapa hal yakni (1) keadaan fisik, (2) pengaruh massa dan karakter elektron, (3) konjugasi, dan (4) ikatan hidrogen (Glendening dkk., 2012). Berdasarkan beberapa faktor ini rentang vibrasi hasil eksperimen dan hasil perhitungan teoritik kemungkinan diakibatkan oleh besarnya efek induksi atau efek resonansi dalam keadaan molekular hal ini disebabkan dalam simulasi komputasi, molekul dianggap dalam wujud gas sedangkan dalam eksperimen laboratorium molekul karbamida tersebut dalam bentuk padatan, lebih rinci hasil analisis termokimia molekul karbamida disajikan pada Tabel 2. Selain itu, pemilihan basis set juga cukup mempengaruhi akurasi perhitungan, semakin tinggi tingkat basis set yang digunakan, maka akurasi perhitungan juga semakin tinggi. 


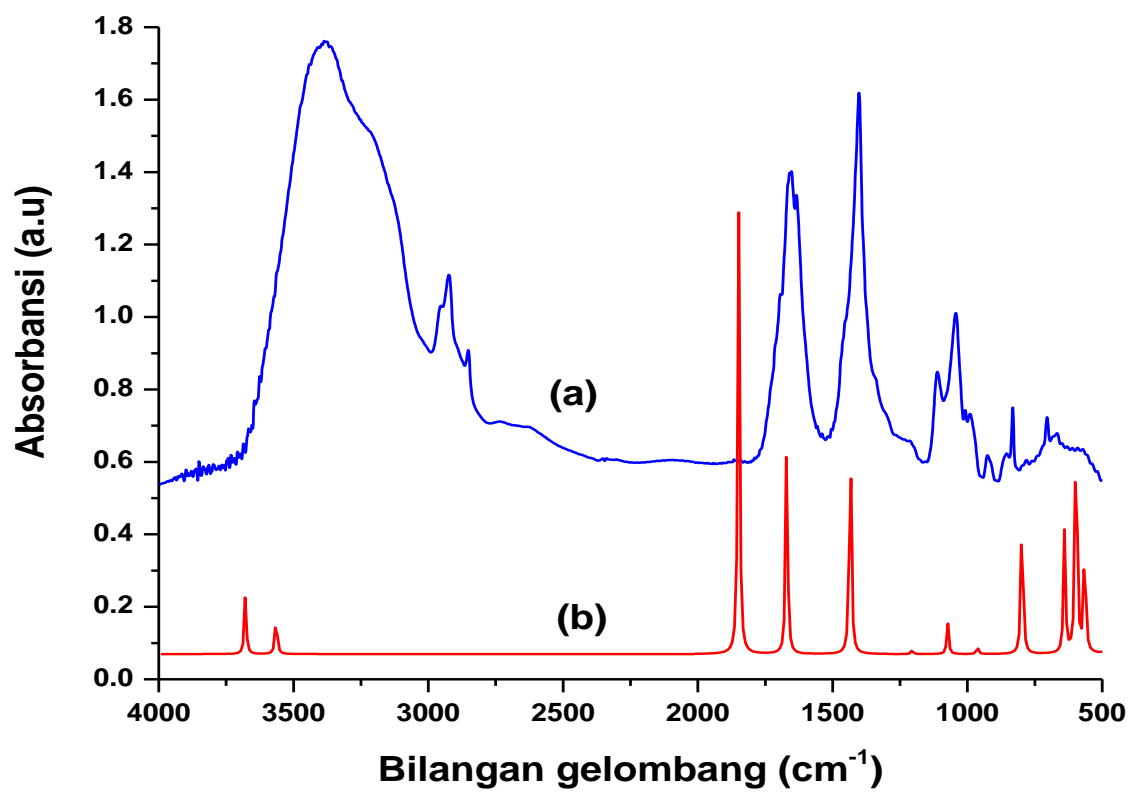

Gambar 4. Perbandingan spectrum FTIR molekul karbamida (a) hasil eksperimen (b) hasil perhitungan secara komputasi

Tabel 2. Hasil analisis termokimia secara teoritik

\begin{tabular}{|c|l|r|c|}
\hline No & \multicolumn{1}{|c|}{ Aspek Termokimia } & \multicolumn{1}{c|}{ Nilai } & Unit \\
\hline 1 & Koreksi Zero-point & 0,064148 & Hartree/Partikel \\
\hline 2 & Koreksi Panas (Energi) & 0,068476 & Hartree/Partikel \\
\hline 3 & Koreksi Panas (Entalpi) & 0,06942 & Hartree/Partikel \\
\hline 4 & Koreksi Panas (Energi bebas Gibbs) & 0,037907 & Hartree/Partikel \\
\hline 5 & Jumlah Elektronik dan Energi Zero-point & $-225,196$ & Hartree/Partikel \\
\hline 6 & Jumlah Elektronik dan Energi Panas & $-225,192$ & Hartree/Partikel \\
\hline 7 & Jumlah Elektronik dan Energi Entalpi & $-225,191$ & Hartree/Partikel \\
\hline 8 & Jumlah Elektronik dan Energi Bebas & $-225,223$ & Hartree/Partikel \\
\hline
\end{tabular}

\section{KESIMPULAN}

Perbandingan panjang ikatan karbamida sebelum dan sesudah optimasi menunjukkan hasil yang sesuai hipotesis dengan rata-rata selisih panjang ikatan $\sim 0,01 \AA$ dan sudut ikatan sekitar $\sim 0,2^{\circ}$. Selanjutnya, Modus vibrasi ikatan molekul karbamida secara karakteristik terlihat di daerah bilangan gelombang $1654 \mathrm{~cm}^{-1}$ untuk regangan $\mathrm{C}=\mathrm{O}$ karbonil dan $1397 \mathrm{~cm}^{-1}$ untuk regangan $\mathrm{C}-\mathrm{N}$, sedangkan dari hasil observasi komputasi vibrasi regangan $\mathrm{C}=\mathrm{O}$ karbonil dan regangan $\mathrm{C}-\mathrm{N}$ berada pada bilangan gelombang $1840 \mathrm{~cm}^{-1}$, dan $1426 \mathrm{~cm}^{-1}$. Selanjutnya, modus vibrasi regangan ikatan N-H berada di daerah bilangan gelombang $3387 \mathrm{~cm}^{-1}$ sedangkan hasil perhitungan diperoleh pada bilangan gelombang $3556 \mathrm{~cm}^{-1}$.

\section{DAFTAR PUSTAKA}

Frisch, M. J., G. W. Trucks, H. B. Schlegel, G. E. Scuseria, M. A. Robb, J. R. Cheeseman, V. G. Zakrewski, J. A. Montgomery, Jr., R. E. Startmann, J. C. Buratn, S. Dapprich, J. M. Millam, A. D. Daniels, K. N. Kudin, M. C. Strain, O. Farkas, J. Tomasi, V. Barone, M.Cossi, R. Cammi, B. Menucci, C. Pomelli, C. 
https://jurnal.unsulbar.ac.id/index.php/saintifik

Adamo, S. Clifford, J. Ochterski, G. A. Petersson, P. Y. Ayala, Q. Cui, K. Morokuma, D. K. Malick, A. D. Rabuck, K. Raghavachari, J. B. Foresman, J. Cioslowski, J. V. Ortis, A. G. Baboul, B. B. Stefanov, G. Liu, A. Liashenko, P. Piskorz, I. Komaromi, R. Gomperts, R. L. Martin, D. J. Fox, T. Keith, M. Al-Laham, C. Y. Peng, A. Nayakkara, C. Gonzales, M. Challacombe, P. M. W. Gill, B. Johnson, W. Chen, M. W. Wong, J. L. Andreas, C. Gonzales, M. Head-Gordon, E. S. Reploge and J. A. Pople. 2003. Gausian 03 Rev. E.01., Gausian, Inc., Pittsburgh.

Govindarajan, M., K. Ganasan, S. Periandy, and S. Mohan. 2010. "Spectrochimica Acta Part A : Molecular and Biomolecular Spectroscopy DFT ( LSDA , B3LYP and B3PW91) Comparative Vibrational Spectroscopic Analysis of Acetonaphthone." Spectrochimica Acta Part A: Molecular and Biomolecular Spectroscopy 76(1):12-21.

Glendening, E. D., Landis, C. R. \& Weinhold, F. Natural bond orbital methods. Wiley Interdiscip. Rev. Comput. Mol. Sci. 2, 1-42 (2012).

Grdadolnik, Jože and Yves Maréchal. 2002. "Urea and Urea-Water Solutions - An Infrared Study." Journal of Molecular Structure 615(1-3):177-89.

Hastiawan, Juliandri. 2013. "Density Functional Theory Untuk Penentuan Geometri Dan Karakteristik Ikatan Dari Kompleks Ni ( II) -Dibutilditiokarbamat Dan Co ( II ) -Dibutilditiokarbamat.” (II):197-202.

Kusuma, Sekar and Tri Windarti. 2013. "Jurnal Kimia Sains Dan Aplikasi Kitosan Sebagai Bahan Dasar Drug Delivery : Studi Interaksi Segmen Dimer Kitosan Dengan Vitamin C Secara Komputasi Ab Initio Dan Eksperimen." 16(2):63-68.

Manivannan, M., Tamil Nadu, S. Rajendran, Tamil Nadu, and Tamil Nadu. 2011. "Investigation Of Inhibitive Action Of Urea- Zn ${ }^{2+}$ System In The Corrosion Control Of Carbon Steel In Sea Water.” 3(11):8048-60.

Morrison, Carole A. and Muhammad M. Siddick. 2003. "Determining the Strengths of Hydrogen Bonds in Solid-State Ammonia and Urea : Insight from Periodic DFT Calculations." (3).

Pongajow, N. T. and Iwan Hastiawan. 2017. "Penentuan Geometri Dan Karakteristik Ikatan Senyawa Kompleks Ni(II)-Dibutilditiokarbamat Dengan Metode Density Functional Theory.” 7(II):33-36.

Premkumar, S., A. Jawahar, T. Mathavan, M. Kumara Dhas, and A. Milton Franklin Benial. 2014. "Vibrational Spectroscopic and DFT Calculation Studies of 2-Amino-7-Bromo-5- Number of Figures." Spectrochimica Acta Part A: Molecular And Biomolecular Spectroscopy.

Sundaraganesan, N., G. Mariappan, and S. Manoharan. 2012. "Spectrochimica Acta Part A : Molecular and Biomolecular Spectroscopy Molecular Structure and Vibrational Spectroscopic Studies of Chrysin Using HF and Density Functional Theory." Spectrochimica Acta Part A: Molecular and Biomolecular Spectroscopy 87:67-76. 